University of New Hampshire

University of New Hampshire Scholars' Repository

$1-1-2016$

\title{
Tradeoffs between three forest ecosystem services across the state of New Hampshire, USA: Timber, Carbon, and Albedo
}

\author{
David A. Lutz \\ Dartmouth College \\ Elizabeth A. Burakowski \\ University of New Hampshire, Durham, elizabeth.burakowski@unh.edu \\ Mackenzie B. Murphy \\ Dartmouth College \\ Mark E. Borsuk \\ Dartmouth College
}

Rebecca M. Niemiec

Dartmouth College

See next page for additional authors

Follow this and additional works at: https://scholars.unh.edu/ersc

Comments

This is an article published by Ecological Society of America (ESA) in Ecological Applications in 2016, available online: https://dx.doi.org/10.1890/14-2207

\section{Recommended Citation}

Lutz, DA, EA Burakowski, MB Murphy, ME Borsuk, RM Niemiec, and RB Howarth. 2016. Tradeoffs between three forest ecosystem services across the state of New Hampshire, USA: Timber, Carbon, and Albedo. Ecological Applications 26(1): 146-161. https://dx.doi.org/10.1890/14-2207

This Article is brought to you for free and open access by the Institute for the Study of Earth, Oceans, and Space (EOS) at University of New Hampshire Scholars' Repository. It has been accepted for inclusion in Earth Systems Research Center by an authorized administrator of University of New Hampshire Scholars' Repository. For more information, please contact Scholarly.Communication@unh.edu. 


\section{Authors}

David A. Lutz, Elizabeth A. Burakowski, Mackenzie B. Murphy, Mark E. Borsuk, Rebecca M. Niemiec, and Richard B. Howarth 


\title{
Trade-offs between three forest ecosystem services across the state of New Hampshire, USA: timber, carbon, and albedo
}

\author{
David A. Lutz, ${ }^{1,6}$ Elizabeth A. Burakowski, ${ }^{2,3}$ Mackenzie B. Murphy, ${ }^{4}$ Mark E. Borsuk, ${ }^{4}$ \\ Rebecca M. Niemiec, ${ }^{1,5}$ and Richard B. Howarth ${ }^{1}$ \\ ${ }^{1}$ Environmental Studies Program, Dartmouth College, Hanover, New Hampshire 03755 USA \\ ${ }^{2}$ National Center for Atmospheric Research, Climate and Global Dynamics Division, Boulder, Colorado 80305 USA \\ ${ }^{3}$ Earth Systems Research Center, Institute for the Study of Earth Oceans, and Space, University of New Hampshire, Durham, \\ New Hampshire 03824 USA \\ ${ }^{4}$ Thayer School of Engineering, Dartmouth College, Hanover, New Hampshire 03755 USA \\ ${ }^{5}$ Emmett Interdisciplinary Program in Environment and Resources, School of Earth Sciences, Stanford University, Stanford, \\ California 94305 USA
}

\begin{abstract}
Forests are more frequently being managed to store and sequester carbon for the purposes of climate change mitigation. Generally, this practice involves long-term conservation of intact mature forests and/or reductions in the frequency and intensity of timber harvests. However, incorporating the influence of forest surface albedo often suggests that long rotation lengths may not always be optimal in mitigating climate change in forests characterized by frequent snowfall. To address this, we investigated trade-offs between three ecosystem services: carbon storage, albedo-related radiative forcing, and timber provisioning. We calculated optimal rotation length at 498 diverse Forest Inventory and Analysis forest sites in the state of New Hampshire, USA. We found that the mean optimal rotation lengths across all sites was $94 \mathrm{yr}$ (standard deviation of sample means = $44 \mathrm{yr}$ ), with a large cluster of short optimal rotation lengths that were calculated at high elevations in the White Mountain National Forest. Using a regression tree approach, we found that timber growth, annual storage of carbon, and the difference between annual albedo in mature forest vs. a post-harvest landscape were the most important variables that influenced optimal rotation. Additionally, we found that the choice of a baseline albedo value for each site significantly altered the optimal rotation lengths across all sites, lowering the mean rotation to $59 \mathrm{yr}$ with a high albedo baseline, and increasing the mean rotation to $112 \mathrm{yr}$ given a low albedo baseline. Given these results, we suggest that utilizing temperate forests in New Hampshire for climate mitigation purposes through carbon storage and the cessation of harvest is appropriate at a site-dependent level that varies significantly across the state.
\end{abstract}

Key words: albedo; climate mitigation; ecological economics; ecosystem services; forest carbon storage; forest ecology; forest management; temperate forests; White Mountain National Forest, New Hampshire, USA

\section{INTRODUCTION}

Roughly $27 \%$ of anthropogenic emissions of carbon dioxide are sequestered in terrestrial ecosystems (Le Quéré et al. 2013), and the majority of this storage occurs in forested landscapes where it is stored in stem and wood biomass. Markets for forest-based carbon offsets have been designed to take advantage of this potential carbon sink through both formal

Manuscript received 21 November 2014; revised 10 April 2015; accepted 21 April 2015. Corresponding Editor: A. D. McGuire.

${ }^{6}$ E-mail: David.a.Lutz@dartmouth.edu regulatory frameworks, for instance the United Nation's Clean Development Mechanism (Galik et al. 2014) and the California Environmental Protection Agency's Air Resources Board, as well as through voluntary mechanisms (Hurteau et al. 2013). A large focus of forest biomass climate mitigation strategies has focused on tropical rainforests (Gibbs et al. 2007), yet as of late, domestic funding of such strategies in Europe and North America have garnered interest in temperate forests as well (Tittmann and Yeh 2013). In response to these incentives, temperate forest ecosystems are increasingly being managed to provide such climateregulating ecosystem services (Canadell and Raupach 
2008, Fahey et al. 2010, Law and Harmon 2011). As a result, understanding how forest management influences the total storage of forest carbon has been a particular point of interest in the research and management communities (Keith et al. 2014).

Previous modeling studies of boreal and temperate forests in the scientific literature have generally indicated that incorporating the value of carbon sequestration leads to long optimal rotation lengths (van Kooten et al. 1995, Kaipainen et al. 2004, Price and Willis 2011). As prices for carbon increase, rotation lengths also increase, with complete conservation eventually being realized at high prices (Chladná 2007, Gutrich and Howarth 2007, Liski et al. 2011). While there are methodologies to incorporate partial and limited harvest so as to increase net primary production and rates of carbon storage temporarily (Hardiman et al. 2013), for the most part these efforts have a small influence on total carbon storage. Subsequently, most forest carbon-offset projects are designed around the conservation of intact forests and the elimination of most harvest.

A wrinkle in the existing forest carbon conservation paradigm comes from a well-established line of research indicating that forest ecosystems interact with the atmosphere through biogeophysical mechanisms in addition to gaseous exchange (Bonan et al. 1995, Bonan 2008, Jackson et al. 2008). In northern latitudes, boreal and temperate forest ecosystems that are frequently covered by snowfall have been found to influence climate substantially through surface-albedo-related radiative forcing; in some cases, this forcing outweighs that of storage sequestration in forest biomass (Betts 2000, Chapin et al. 2000, Kirschbaum et al. 2011). This is mainly thought to be due to the low albedo of conifer needle-leaf tree species (Sturm 2005), as well as low growth rates and reduced carbon storage in the forests themselves (Lutz and Howarth 2014). As a result, the existing mechanism for mitigating climate change in forests, conservation and the elimination of harvest, may not necessarily generate a cooling influence on global climate when albedo is considered (Bright et al. 2014). Conversely, the management mechanism for increasing albedo requires the removal of forest biomass, which counteracts the attempt to store carbon in woody biomass. In order to properly and optimally design efficient and effective climate change mitigation policies, it is therefore important to understand how these two climate-regulating ecosystem services trade off under different management regimes (Thompson et al. 2009, Anderson et al. 2011, Bright et al. 2011, 2012). However, as forests are complex ecosystems that vary in species composition, growth rate, and carbon storage over space and time, a detailed understanding of the exact trade-offs between the benefits of carbon storage and increased albedo-related radiative forcing remains elusive for many temperate and boreal forests.
The most recent developments in calculating the overall balance between carbon storage and albedo in forested landscapes have been the result of careful empirical models of forest ecosystems as informed by forest growth data coupled with albedo measurements from satellite sensors (Bright et al. 2011, 2012, 2014, Cherubini et al. 2013). Generally these studies have occurred in boreal forests, where findings suggest that species cover, particularly whether the forest is broadleaved deciduous or evergreen coniferous, as well as stand age, temperature, and latitude (Bright et al. 2013, Lukeš et al. 2013) influence surface albedo. While these studies have relied upon the suite of MODIS albedo products, MOD10A (Hall and Riggs 2007), and MCD43A (Schaaf et al. 2002), empirical models of albedo dynamics have been generated (Bright et al. 2013) and used (Lukeš et al. 2013, 2014, Otto et al. 2014) specifically for this purpose. Although a few studies have used similar methods to examine temperate forests (Thompson et al. 2009, Lutz and Howarth 2014), these efforts looked at broad categories of forest type and did not examine enough sites to understand subtle variations across the landscape. It is important to note that, while trade-offs between these biogeophysical forcings have been estimated before at coarse (e.g., Zhao and Jackson 2014) and fine scales (Williams et al. 2014), these studies have not included methodologies to relate forcings to each other using a similar unit of analysis or value.

The calculation of net benefits from carbon storage in forested ecosystems is generally based on an expected baseline of forest growth (Malmsheimer et al. 2011). From this baseline, calculations can be made to ensure that management actions have generated a benefit (i.e., a net increase in carbon storage) when compared to a situation when no actions were taken. This is defined by the term "additionality" and is a requisite for climate change policy frameworks. Calculating national baselines of forest growth is a contentious process with serious consequences for the total credited emissions allocated to forest projects (Griscom et al. 2009). Previous studies that have included trade-offs between albedo and carbon storage have used available satellite records of albedo (Bright et al. 2012, 2014, Lutz and Howarth 2014), yet it is uncertain whether or not that is a statistically reliable sample of measurements upon which to categorize future behavior of albedo. Thus, the choice of which annual albedo values are selected to compare to future albedo, what we deem an albedo baseline, is critically important for the proper implementation of albedo into climate policy.

In this study, we seek to address this lack of understanding among the trade-offs between multiple ecosystem services in New Hampshire forest landscapes by focusing on three related questions: (1) Is the method of reducing timber harvest in forests an optimal strategy in general for climate mitigation across diverse temperate forests? (2) If not, under what 
circumstances should harvest for albedo-induced radiative cooling or lack of harvest for carbon sequestration be emphasized? (3) Does the selection of an albedo baseline have a significant influence on the optimal rotation length when timber, albedo, and carbon are considered?

We hypothesize that although most temperate forest climate mitigation projects are focused on a limited-harvest approach, this methodology may not be optimal when albedo is included in ecosystems that receive frequent snowfall. We also expect that the ratio between forest growth rate and post-harvest albedo is the key metric through which to determine the best harvest rotation length. Finally, we predict that year-to-year variation in measured albedo may dramatically impact optimal rotation length when alternative albedo baselines are selected for use in the calculation of site net present value (NPV). Collectively, our findings have important implications for guiding the direction and design of climate mitigation projects in the state's forests and throughout the New England region.

\section{Meth ODS}

\section{Study area and sites}

Our study examined a network of 498 forest inventory plots throughout the state of New Hampshire, USA, which represent a variety of forest types, encompassing over a dozen dominant forest species common throughout the New England region (Fig. 1). The dominant forest type in New Hampshire is categorized as northern hardwood, which usually contains a combination of maples (Acer sacccharum and $A$. rubrum), beech (Fagus grandifolia), birch (Betula alleghaniensis and B. papyrifera), and occasionally ash (Fraxinus americana) and Eastern hemlock (Tsuga canadensis). In the northern region of the state and at higher elevations, particularly in the White Mountain National Forest, the spruce-fir forest, containing red spruce (Picea rubens) and balsam fir (Abies balsamea), dominates the landscape. In southern New Hampshire, pine-oak forests, containing white pine (Pinus alba), red pine (P. resinosa), red oak (Quercus rubrum), and occasionally other hardwoods are present, particularly in areas once used for agriculture or pasture. Hemlock forests, dominated by Eastern hemlock, and aspen-birch forests, containing two species of aspen (Populus grandidentata and P. tremuloides), are less common forest types found mainly in riparian valleys. In addition to the dominant forest species that occur in these broad major forest types, New Hampshire contains an additional 71 tree species, many of which are uncommon but occasionally will become a significant part of the dominant canopy, namely gray birch (B. populifolia), black cherry (Prunus serotina), green ash ( $F$. pennsylvanica), striped maple (A. pensylvanicum), and American elm (Ulmus americana).

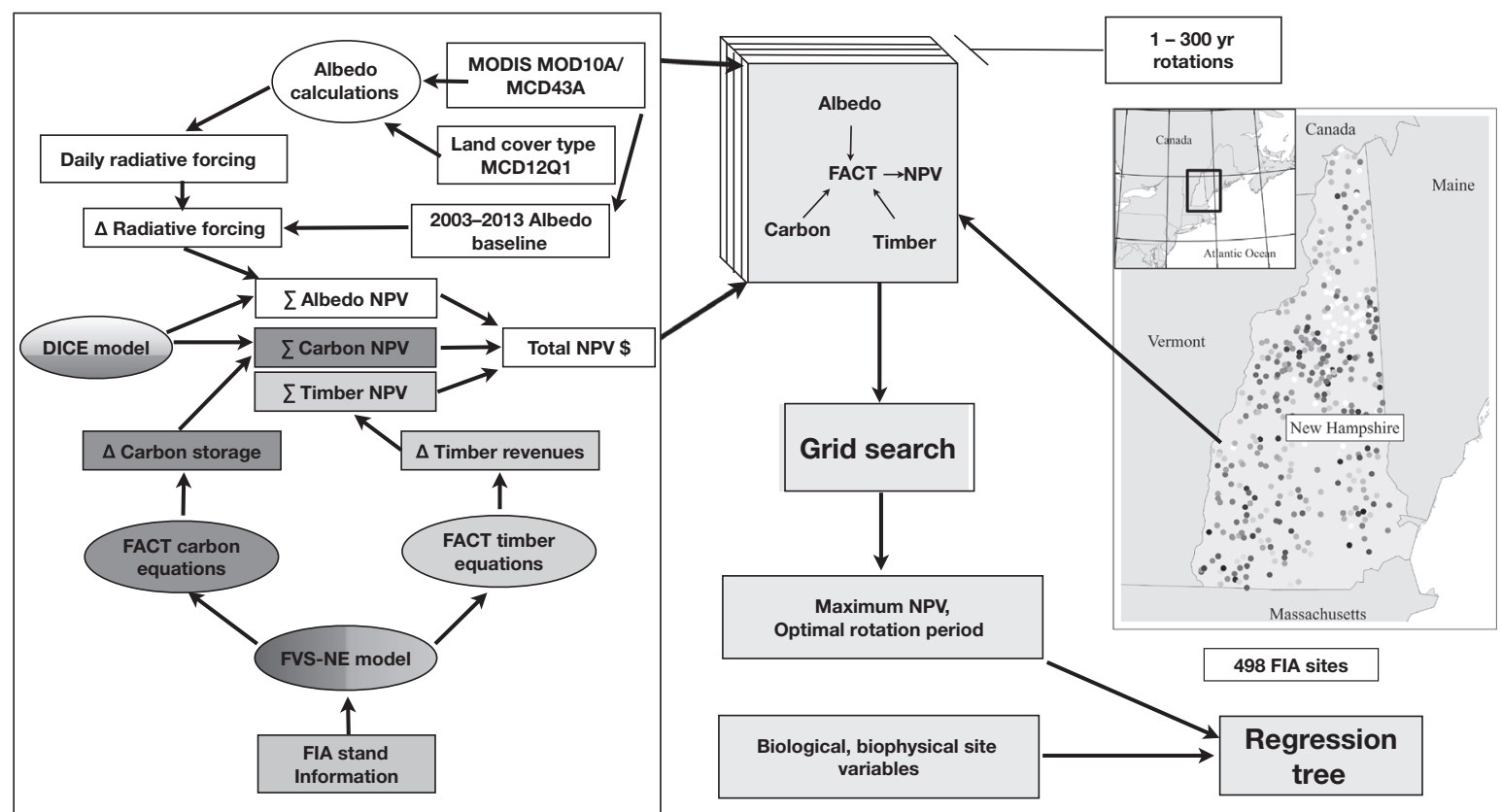

FIG. 1. A graphical representation of the methodologies used in this study. Each of the 498 FIA (Enhanced Forest Inventory and Analysis) sites in New Hampshire (USA) was simulated 299 times, with rotation lengths ranging 1-300 yr. Models include the FACT (Forest Albedo Carbon and Timber) and FVS-NE (Northeast Variant of the Forest Vegetation Simulator), inputs include net present value (NPV; US\$) calculations; $\Delta$ refers to change in, $\Sigma$ to sum of. 
The forest plots used in this analysis were inventoried through the Enhanced Forest Inventory and Analysis (FIA) Program of the U.S. Department of Agriculture (USDA) and the Forest Service (Bechtold and Patterson 2005). Through the FIA program, a systematically scattered series of forest plots are inventoried annually throughout the United States. Sampling design for the FIA program is constructed in a way that results in a nationwide sampling distribution of one plot for every $2428 \mathrm{ha}\left(24.28 \mathrm{~km}^{2}\right)$ in areas classified as forests (Bechtold and Patterson 2005). Additionally, the sampling design is constructed so as to reduce bias in tree species distributions (Bechtold and Patterson 2005, McRoberts et al. 2005, Zhu et al. 2012). Forest plots were constructed through a four-point cluster design containing four subplots of a radius of $7.32 \mathrm{~m}$, wherein trees $12.7 \mathrm{~cm}$ in diameter at breast height (dbh; 1.37 $\mathrm{m}$ above ground) are measured and recorded; four $2.07 \mathrm{~m}$ fixed-radius microplots in which saplings and seedlings are measured and recorded; and four 18.0 $\mathrm{m}$ fixed-radius macroplots, which are used when large trees are encountered (Bechtold and Patterson 2005). For our analysis, we initially relied on a base collection of 2083 forest plots collected from 2003-2012. We removed plots that were defined as unstocked with timber, contained too few records to model accurately, or were not located in an area in which sufficient satellite data for the estimation of albedo were available, and thus refined our analysis to a total of 498 plots.

\section{Forest growth modeling}

For each of our sites, we utilized the Northeast Variant of the Forest Vegetation Simulator (FVS-NE) model (Wykoff et al. 1982, Dixon 2002, Crookston and Dixon 2005) to simulate growth following a clearcut harvest for a period of $200 \mathrm{yr}$. The FVS model is a distance-independent individual-tree growth model, which generally relies upon incremental diameter growth in large trees within each plot (Crookston and Dixon 2005). Diameter growth in FVS is influenced by several site characteristics including aspect, elevation, and general habitat type and further constrained by crown position and other structural attributes which determine the overall growth rate, mainly stem density (Crookston and Dixon 2005). Small trees are simulated by a heightgrowth approach, a methodology that calculates incremental diameter growth based upon height growth as well as site characteristics such as a crown competition factor, stand density, crown ratio, and social position of the individual (Crookston and Dixon 2005). FVS uses species specific allometric equations for biomass estimates (Jenkins et al. 2003, Nunery and Keeton 2010) and thus can be used to simulate above- and belowground carbon dynamics through time. Specifically, FVS-NE relies upon growth and yield equations from the NE-TWIGS model (Hilt and Teck
1989). FVS-NE has been validated for northern hardwood forest ecosystems (Yaussy 2000), as well as for simulating the growth of forests post-management (Crookston and Dixon 2005, Ray et al. 2009). An analysis of the FVS-NE in predicting the total tree height and 5-yr diameter and height increment for the 20 most abundant species in the northeastern United States found that the model's estimations performed moderately well and did not show any major spatial issues (Russell et al. 2013).

For each site, we simulated forest growth for 200 $\mathrm{yr}$ at increments of $5 \mathrm{yr}$, assuming static present-day climate. At the first year of each simulation, we prescribed the removal of all trees greater than 2 inches $(1$ inch $=2.54 \mathrm{~cm}) \mathrm{dbh}$, with no additional harvest for the remaining time period. We selected this dbh limit as it conforms to USDA guidelines for group selection harvest (Lamson and Leak 2000) and is commonly used in other clear-cut simulations using FVS (Nunery and Keeton 2010, Schwenk et al. 2012). Modeling regeneration in FVS-NE requires careful tuning and necessitates incorporating natural regeneration parameters for simulations including harvest. For this information, we relied upon previously published field data from several sources (Leak 2005, Nunery and Keeton 2010) and used in other studies using FVS-NE simulations (Nunery and Keeton 2010, Mika and Keeton 2014) and followed the approach of Mika and Keeton (2014). We collected individual stand reports for every $5 \mathrm{yr}$ of the simulations, which included the simulated number of individuals, their sizes and ages, species, and position in the canopy. Additionally, stand structural attributes such as canopy closure and stand biomass were collected along with estimates of carbon storage based on allometric equations specific to species groups (Jenkins et al. 2003). We did not incorporate changes in climate or natural disturbance through windthrow in our forest simulations.

\section{Timber and carbon modeling}

To calculate the total quantity of timber volume from each site, we used the Forest Albedo Carbon and Timber (FACT) model (Gutrich and Howarth 2007, Lutz and Howarth 2014) to estimate quantities of pole- and sawtimber in each stand. The FACT model relies upon the curvilinear relationship that exists between harvestable timber volume $(V)$ and stand age

$$
V(s)=\left\{\begin{array}{cc}
\alpha_{0}\left(1-\left(1-\alpha_{1}\right)^{\left(s-\alpha_{2}\right)}\right) & s \geq \alpha_{2} \\
0 & \text { slt } \alpha_{2}
\end{array}\right.
$$

where $\alpha_{0}$ is the maximum timber volume for the site, $\alpha_{1}$ is the volume growth rate, $\alpha_{2}$ is the youngest stand age when a stand can be harvested and contain valuable timber, and $s$ is the stand age (Gutrich and Howarth 2007). For each stand, we calculated this relationship and its parameters based on the volumetric outputs 
of FVS-NE post-harvest through a process of optimization described in the Appendix and based on the methods of Gutrich and Howarth (2007). We divided timber volume into sawtimber using the equation

$$
f_{\text {saw }}(s)=\left\{\begin{array}{cc}
0 & \frac{\beta_{0} s}{\left(s+\beta_{1}\right)}-\beta_{2} l t 0 \\
\beta_{0} s /\left(s+\beta_{1}\right)-\beta_{2} & \frac{\beta_{0} s}{\left(s+\beta_{1}\right)}-\beta_{2} \in[0,1] \\
1 & \frac{\beta_{0} s}{\left(s+\beta_{1}\right)}-\beta_{2}>1
\end{array}\right.
$$

in which $\beta_{0}, \beta_{1}$, and $\beta_{2}$ are coefficients, with $f_{\text {saw }}$ representing the proportion of timber that is sawtimber, and poletimber representing the remaining fraction of timber volume (Gutrich and Howarth 2007, Lutz and Howarth 2014).

To represent the appropriate costs associated with short rotation lengths, we implemented mowing costs that occurred when there was a timber harvest, yet when no pole- or sawtimber stock was present at the site (i.e., when the harvest time, $t$, was less than the minimal stand age with timber volume, $\alpha_{2}$ ). Costs for mowing and maintaining fields in the New England region have been estimated to be between US\$80 and US\$486 per ha (Oehler 2003), depending on site conditions. To account for this, we reasoned that as a site became overgrown, the cost per clearing increases and as such, we estimated that mowing costs, $M_{\mathrm{c}}$, increased proportionately with stand age $s$, to a maximum value at $\alpha_{2}$ :

$$
M_{\mathrm{c}}=\left\{\begin{array}{cc}
\mathrm{LC}+0.835391\left(\frac{s}{\alpha_{2}-1} \times \mathrm{HC}\right) & \text { slt } \alpha_{2} \\
0 & s \geq \alpha_{2}
\end{array}\right.
$$

where $\mathrm{LC}$ and $\mathrm{HC}$ are the low and high, respectively, estimates of mowing cost per hectare adjusted for inflation and $\alpha_{2}$ represents the youngest age at which the stand will contain timber of value.

Forest carbon storage was also calculated for each site using the FACT model, with inputs for each stand based on corresponding FVS-NE simulations of that stand. The FVS-NE model generates estimates of carbon storage through the use of regional allometric equations (Jenkins et al. 2003, Nunery and Keeton 2010), and provides information on carbon storage within above- and belowground live biomass, the forest floor in dead and downed wood, and through standing dead wood. Stand simulations in FVS-NE of these carbon pools were used to generate relationships between stand age and carbon storage in order to generate net carbon uptake, a method identical to the process detailed Gutrich and Howarth (2007), but using FVS-NE simulated carbon tables from each stand instead of Carbon On-Line Estimator (COLE) 1605 $\mathrm{b}$ reports (reports to the $1605 \mathrm{~b}$ program of the United States Energy Information Administration, which provide voluntary reporting of greenhouse gas emissions by public and private entities). We did not model soil carbon, as it is not simulated in FVS-NE owing to its variable nature from site to site (Schwenk et al. 2012, Mika and Keeton 2014) and frequent lack of inclusion in life-cycle analysis and offset protocols (Law and Harmon 2011). Carbon stored in long-lived wood products was also modeled in a similar fashion to Gutrich and Howarth (2007).

\section{Albedo data collection}

For each site, we collected snow-free surface albedo from the MODIS Bi-Directional Reflectance Distribution Function (BRDF) Adjusted Albedo product (MCD43A3, v005; Schaaf et al. 2011) from 20022013. Specifically, we used the 500-m spatial resolution 8-d broadband combined Aqua and Terra product. High-quality and snow-free retrievals of directional hemispherical reflectance $\left(\alpha_{\text {ksky }}\right)$ and bihemispherical reflectance $\left(\alpha_{\text {wsky }}\right)$ albedos were linearly interpolated to actual $\left(\alpha_{b s k y}\right)$ albedo assuming an isotropic distribution of diffuse skylight (SKYL) at local solar noon through the equation

$$
\alpha_{\text {bsky }}=\mathrm{SKYL} \times \alpha_{\text {wsky }}+(1-\mathrm{SKYL}) \times \alpha_{\text {ksky }}
$$

where SKYL has been set to 0.2. A sensitivity analysis performed using SKYL values ranging from 0.1 to 0.6 did not yield any significant differences in $\alpha_{\text {bsky }}$ computed from Eq. 3, thus suggesting that the simple linear interpolation captures the majority of the anisotropic dependence of $\alpha_{b s k y}$ on aerosol optical depth and solar zenith angle for snow-free surface albedo.

The number of high-quality snow-covered pixels for the MCD43A3 product was very limited (and in some cases zero) for many of the sites in our analysis. As such, we elected to use the MOD10A1 500-m daily snow-covered shortwave broadband albedo product (Klein and Stroeve 2002, Hall and Riggs 2007). This product is generated for cloud-free snow-covered pixels using the atmospherically corrected MODIS/Terra surface reflectance product (MOD09GHK) and BRDF look-up tables to correct for surface anisotropy based on solar zenith angle, sensor zenith, and relative azimuth together with surface slope, aspect, and MCD12Q1 land cover type (Klein and Stroeve 2002). In MOD10A, snow-covered pixels in non-forested areas are adjusted for anisotropic scattering effects using the DIScrete Ordinates Radiative Transfer (DISORT) model; snow optical properties for forested land cover types, as identified by MCD12Q1, are assumed to be lambertian reflectors. MCD43A3 and MOD10A1 both perform well (biases $<0.05$ ) relative to hyperspectral imagery collected over snow-covered forests and cropland mosaics in the state of New Hampshire (Burakowski et al. 2015).

Both snow-free and snow-covered surface albedo data were retrieved for each FIA site for the period 2002-2013. In order to ensure that each MODIS pixel was spatially and temporally representative of each forest site, and since precise specifics regarding FIA 
plot locations are restricted and fuzzed, we ensured that two criteria were met at each location. Firstly, each site needed to be located in a MCD12Q1 pixel that was surrounded by pixels of the same land cover type in order to determine spatial homogeneity. Secondly, each site needed to remain classified as forested land cover throughout the 2002-2013 MCD12Q1 record. Each site location was paired with the nearest pixel that was consistently classified as cleared (e.g., cropland, grassland, or cropland/natural mosaic) through the 2002-2013 record. This pairing was designed in order to calculate canopy-free albedo retrievals and estimate radiative forcing for each site when harvest was simulated. The mean distance between these pairings was $9.6 \mathrm{~km}$ and a figure showing the distribution of these distances can be found in Appendix: Fig. S11. Although this approach did not generate albedo data directly for each site, it provided albedo data from locations generally sharing the same climate and soil influences, and follows the general approach of Lutz and Howarth (2014). Similarly, we constructed a baseline mature-forest and a baseline cleared albedo for each site by averaging the mean monthly values as collected by the MODIS data over the 11-yr period.

\section{Net radiative flux modeling}

In general, we calculated daily shortwave net radiative flux from albedo following the approach of Lutz and Howarth (2014) through the use of the FACT model. In this methodology, shortwave radiation flux from a forest stand to the atmosphere is directly related to the incoming top-of-the-atmosphere solar radiation, surface albedo, and two general characteristics of the atmosphere

$$
\mathrm{RF}_{\mathrm{fs}}=R_{\mathrm{TOA}} \alpha_{\mathrm{bsky}} f_{\mathrm{a}}
$$

in which $\mathrm{RF}_{\mathrm{fs}}$ is the shortwave radiation flux, $R_{\mathrm{TOA}}$ is the top of the atmosphere solar radiation, calculated through several equations describing planetary rotation (Kalogirou 2009, Bright et al. 2012), $\alpha_{\text {bsky }}$ is the surface albedo of the forest stand, and $f_{\mathrm{a}}$ is a measure of two-way atmospheric transmittance. The calculation of $f_{\mathrm{a}}$ depended upon a measurement of the clearness of the atmosphere, $K_{\mathrm{T}}$, at month $j$, and transmittance of the atmosphere, $T_{\mathrm{a}}$, through the equation

$$
f_{\mathrm{a}}=K_{\mathrm{T}, j} T_{\mathrm{a}}
$$

as used by Bright et al. (2012). As in Lutz and Howarth (2014) and Bright et al. (2012), we used a global mean of $T_{\mathrm{a}}, 0.854$, and a clearness index derived from monthly data from the NASA Surface meteorology and Solar Energy (SSE) product (NASA 2009).

Forest albedo slowly declines throughout the course of the life of a stand as canopy cover increases and the ground surface is masked by vegetation (Kuusinen et al. 2014b). To account for this change over the life of the stand, we used an exponential decay function that operated between the non-forest annual mean albedo, $\alpha_{c}$, and the mature forest annual mean albedo, $\alpha_{m}$ (Cherubini et al. 2012, Lutz and Howarth 2014). The decay function follows the form

$$
\alpha_{a}=a b^{x}
$$

where $x$ represents the stand age and $a$ represents albedo, and whereupon $b$ is calculated

$$
b=\frac{\alpha_{\mathrm{m}}}{\alpha_{\mathrm{c}}}\left(\frac{t_{0}}{t_{\mathrm{m}}-1}\right)
$$

and $t_{0}$ and $t_{\mathrm{m}}$ represent a stand age of zero and the age in which forest canopy saturates and albedo is at its lowest. The exponential decay rate for each site was dependent upon the simulated structural statistics from FVS-NE, whereby the time to maturity of the stand with respect to albedo was determined to be when canopy cover of the main stratum approached $90 \%$ of the maximum cover reached throughout the 200-yr simulation.

The FACT model generates flows of ecosystem services over a series of annual time steps. Thus, it was necessary to calculate the mean annual radiative flux, $R_{\mathrm{Ta}}$, for each site (Bright et al. 2012)

$$
R_{\mathrm{Ta}}=\frac{\sum_{i-1}^{i=365} \mathrm{RF}_{\mathrm{fs}}}{365}
$$

In order to understand the year-to-year net change in radiative forcing, $\mathrm{RFr}$, as a result of changes in forest cover, we then used the equation

$$
\Delta \mathrm{RFr}_{i}=R_{\mathrm{Ta} i}-R_{\mathrm{Ta} i-1}
$$

where $i$ is the year of the simulation.

\section{Pricing and net present value}

We relied on both market and modeled prices to calculate net present values of timber, net carbon uptake, and albedo in the FACT model. Timber values for saw- and poletimber were based on stumpage values reported by the New Hampshire State Department of Revenue for all three regions of the state from April to November 2014 (values available online). ${ }^{7} \mathrm{We}$ assumed a price increase at a rate of $1.0 \%$ per year based on an analysis by Sendak et al. (2003). Each stand was assigned a region of the state depending upon its geographic position. As the majority of stands were composed of more than one species, we calculated the total stand stumpage value in proportion to the two most dominant tree species as determined by total aboveground biomass throughout the rotation length of the stand.

\footnotetext{
${ }^{7}$ http://www.revenue.nh.gov/mun-prop/property/stumpagevalues.htm
} 
Both carbon and albedo shadow prices were calculated using the 2007-DICE integrated assessment model (Nordhaus 1993, 2008, 2010). Lutz and Howarth (2014) describe how this model may be used to assign shadow prices for both carbon and albedo by estimating changes in social welfare as a result of changes in climate and temperature and their associated damages. Social welfare $(W)$ in DICE is modeled over decadal time steps, and is based on an instantaneous utility function $(U)$, which is dependent on per capita consumption $(c)$ and total population $(L)$, and a discount factor reflecting the relative weight attached to present and future well-being $(R(t)$; Nordhaus 2008)

$$
W=\sum_{t=1}^{T_{\max }} U[c(t), L(t)] R(t) .
$$

We use this equation to derive the shadow price of carbon emissions $\left(V_{c}\right)$ by calculating the change in welfare in response to a one-unit increase in emissions $(E)$ divided by the present-value marginal utility of consumption

$$
V_{c}(t)=\frac{[\partial W / \partial E(t)]}{[\partial W / \partial c(t)]} .
$$

This same technique can be used to calculate the shadow price of one unit of radiative forcing $\left(V_{\mathrm{a}}\right)$ by simply substituting a unit of radiative forcing (RF) for a unit of carbon emissions $(E)$

$$
V_{\mathrm{a}}(t)=\frac{[\partial W / \partial \mathrm{RF}(t)]}{[\partial W / \partial c(t)]} .
$$

As noted by Nordhaus, the shadow price of carbon is highly sensitive to assumptions concerning future $\mathrm{CO}_{2}$ emissions trajectories. For the sake of this analysis, here we limit attention to the case where emissions are chosen optimally at each point in time to maximize social welfare. See Lutz and Howarth (2014) for an analysis of the case where policies are chosen to implement the $2{ }^{\circ} \mathrm{C}$ global warming target embodied in the 2009 Copenhagen Accord.

Estimates of the total net present value of the stand with respect to all three ecosystem services were calculated using the NPV equations for each ecosystem service: timber

$$
\mathrm{NPV}_{\mathrm{t}}=\sum_{i=1}^{\infty} P_{i}\left(s_{h}, s_{h} \times i\right) V_{\mathrm{t}}\left(S_{h}\right) \prod_{t=1}^{s_{h \times i}} \frac{1}{1+r(t)}
$$

where $P$ represents stumpage price, $s_{h}$ is stand age at rotation length $h, V$ is timber volume calculated in Eq. 1, and $r(t)$ is the discount rate, which is calculated endogenously within DICE and ranges from 0.045 to 0.037 , decreasing steadily with time; carbon

$$
\mathrm{NPV}_{\mathrm{c}}=\sum_{i}^{\infty} V_{\mathrm{c}}(t) \Delta C(t) \prod_{i=1}^{t} \frac{1}{1+r(t)}
$$

where $V_{c}(t)$ represents the marginal benefit of carbon sequestration in dollars/ton $(1$ ton $=1 \mathrm{Mg})$ as calculated in Eq. 12 and $\Delta C(t)$ is the annual incremental change in forest stand carbon; and albedo:

$$
\mathrm{NPV}_{\mathrm{a}}=\sum_{t=0}^{\infty} V_{\mathrm{a}}(t) \Delta \mathrm{RF}_{r}(t) \prod_{i=1}^{t} \frac{1}{1+r(t)} .
$$

The total net present value of the forest stand is thus calculated by adding the net present values of each service together

$$
\mathrm{NPV}_{\text {tot }}=\mathrm{NPV}_{\mathrm{t}}+\mathrm{NPV}_{\mathrm{c}}+\mathrm{NPV}_{\mathrm{a}} .
$$

\section{Simulations and statistical analysis}

We simulated each of the 498 forest sites for a total of $1000 \mathrm{yr}$, long enough to minimize truncation error, using the FACT model to generate net present values for each of the three ecosystem services. At each site, we simulated all rotation lengths between 1 and $300 \mathrm{yr}$, thereby generating a total of 300 separate simulations per site. By calculating the total NPV for each rotation length for each site, we were able to estimate the optimal rotation length, whereby the net present value was maximized, using a grid search technique. In order to determine the influence of the albedo baseline on the optimal rotation length, we calculated two other sets of baselines for each site. The first additional baseline $\left(\Delta \alpha_{\max }\right)$ used the maximum monthly albedos from cleared pixels and the minimum monthly albedos from mature forest sites to calculate cleared and mature baseline albedos wherein the difference between the two would be maximized. The second additional albedo baseline $\left(\Delta \alpha_{\min }\right)$ used the minimum monthly albedos from cleared pixels and the maximum monthly albedos from mature forest sites to generate baseline albedos where the difference between the two would be minimized. Choosing these extremes would therefore demonstrate how the selection of baselines could most drastically alter rotation lengths and NPVs.

We assessed the change in optimal rotation length for each site as a function of its ecological and biogeophysical characteristics (Table 1) through the use of a regression tree approach. Regression trees are frequently used in ecological studies to understand the variation in a single response variable, in our case the optimal rotation length, associated with other explanatory variables (Nair et al. 2013). This methodology uses binary recursive partitioning to generate splitting rules to successively reduce variability in the distribution of the response variable across the range of predictor variables for each site (Moisen and Frescino 2002). We chose as the single final tree the largest for which any additional split would increase the improvement score (as measured by the reduction in the sum of squared prediction errors) by more than 
TABLE 1. Relative importance of each of 19 predictor variables on optimal rotation length as calculated in the regression tree algorithm.

\begin{tabular}{|c|c|c|c|c|}
\hline Variable (unit) & Rotation period $(\%)$ & Albedo (\%) & Carbon $(\%)$ & Timber $(\%)$ \\
\hline Latitude $\left({ }^{\circ}\right)$ & 4 & 1 & 1 & 0 \\
\hline Canopy saturation time (yr) & 2 & 0 & 21 & 1 \\
\hline Percentage coniferous & 2 & 0 & 0 & 1 \\
\hline Elevation (feet) & 5 & 0 & 0 & 0 \\
\hline Timber growth rate $(\% / y r)$ & 28 & 5 & 7 & 57 \\
\hline Maximum carbon storage (tons/ha) & 3 & 0 & 50 & 8 \\
\hline Carbon growth rate $(\% / y r)$ & 19 & 5 & 9 & 31 \\
\hline Sawtimber price $\left(\$ / \mathrm{m}^{3}\right)$ & 7 & 0 & 0 & 0 \\
\hline Poletimber price $\left(\$ / \mathrm{m}^{3}\right)$ & 2 & 0 & 0 & 0 \\
\hline Aspect $\left({ }^{\circ}\right)$ & 2 & 0 & 0 & 0 \\
\hline Slope $\left(^{\circ}\right)$ & 2 & 9 & 0 & 0 \\
\hline \multicolumn{5}{|l|}{ Classified forest type (\%) } \\
\hline Broadleaved & 0 & 0 & 0 & 0 \\
\hline Mixed forest & 1 & 0 & 1 & 0 \\
\hline Grassland & 0 & 6 & 1 & 0 \\
\hline Cropland & 1 & 0 & 0 & 0 \\
\hline Natural mosaic & 1 & 1 & 0 & 0 \\
\hline Saturated albedo baseline & 1 & 1 & 0 & 0 \\
\hline Cleared albedo baseline & 8 & 28 & 3 & 0 \\
\hline $\begin{array}{l}\text { Difference between saturated and cleared } \\
\text { baseline }\end{array}$ & 12 & 44 & 5 & 0 \\
\hline
\end{tabular}

Notes: all prices are given in US\$; 1 ton $=1 \mathrm{Mg}, 1 \mathrm{foot}=0.31 \mathrm{~m}$. Each variable is listed by relative overall percentage contribution to the prediction of the response variable. Saturated and cleared albedo baseline, and the difference between the two, were all unitless.

$1 \%$. To understand the relative influence of each site characteristic on optimal rotation length, we also calculated a tree-based measure of relative predictor importance for each variable (Breiman et al. 1984). Importance of a predictor was calculated as the sum of improvement scores across all splits in a tree that involved that predictor. We also calculated this relative importance measure for regression trees in which the net present value of each of the three ecosystem services was used as the response variable.

\section{RESUlTS}

Across all 498 forest sites, the mean optimal rotation length when timber, carbon, and albedo were valued was $\sim 94 \mathrm{yr}$, with a maximum optimal rotation of $298 \mathrm{yr}$, a minimum optimal rotation length of 3 $\mathrm{yr}$, and a standard deviation of $\sim 43$ yr. In general, optimal rotation lengths shortened from south to north across the state (Fig. 2). Optimal rotation lengths longer than $200 \mathrm{yr}$ were generally confined to the southern third of the state, while extremely short rotation lengths below $10 \mathrm{yr}$ could be found throughout the state. A cluster of short optimal rotation lengths occurred at high elevations near Mount Washington within the White Mountain National Forest. Site-to-site variation differed dramatically; in several instances, sites with long ( $>200 \mathrm{yr}$ ) and short $(<10 \mathrm{yr})$ optimal rotation lengths were located within
$10 \mathrm{~km}$ of each other, thus indicating that specific site variables can drastically change optimal strategy of forest harvest.

The magnitude of the optimal rotation length influenced the total net present value of the stand. To examine this, we grouped all forest sites into three categories, those with short $(<10 \mathrm{yr} ;$ mean value $\$ 5267.78 / \mathrm{ha}, \mathrm{SD}=\$ 943.28 / \mathrm{ha})$, medium (89-99 yr; mean value $\$ 4338.39 / \mathrm{ha}, \mathrm{SD}=\$ 1261.76 / \mathrm{ha})$, and long optimal rotation lengths ( $>200 \mathrm{yr}$, mean value $\$ 2942.00$ / ha, $\mathrm{SD}=\$ 998.39 / \mathrm{ha})$. While there was no statistical difference between the short and medium rotation groups with respect to total NPV, both the short $\left(t_{36}\right.$ $=7.18, P<0.0001)$ and medium $\left(t_{45}=4.67, P<\right.$ $0.0001)$ rotation groups differed significantly $(P<0.05)$ from the long rotation group (Fig. 4). The net present value for each ecosystem services (timber, carbon, and albedo) generally differed depending upon the length of the optimal rotation length (Fig. 5). In sites with a very short optimal rotation, albedo was most frequently the most valuable ecosystem service and harvesting for timber yielded a substantial cost due to the price of mowing. The value of carbon was substantial for both medium and long rotation lengths; timber value contributed in medium, but not in long rotation length sites.

We examined the influence of each of 19 factors upon the overall optimal rotation length across all 498 forest sites using a regression tree analysis. The 


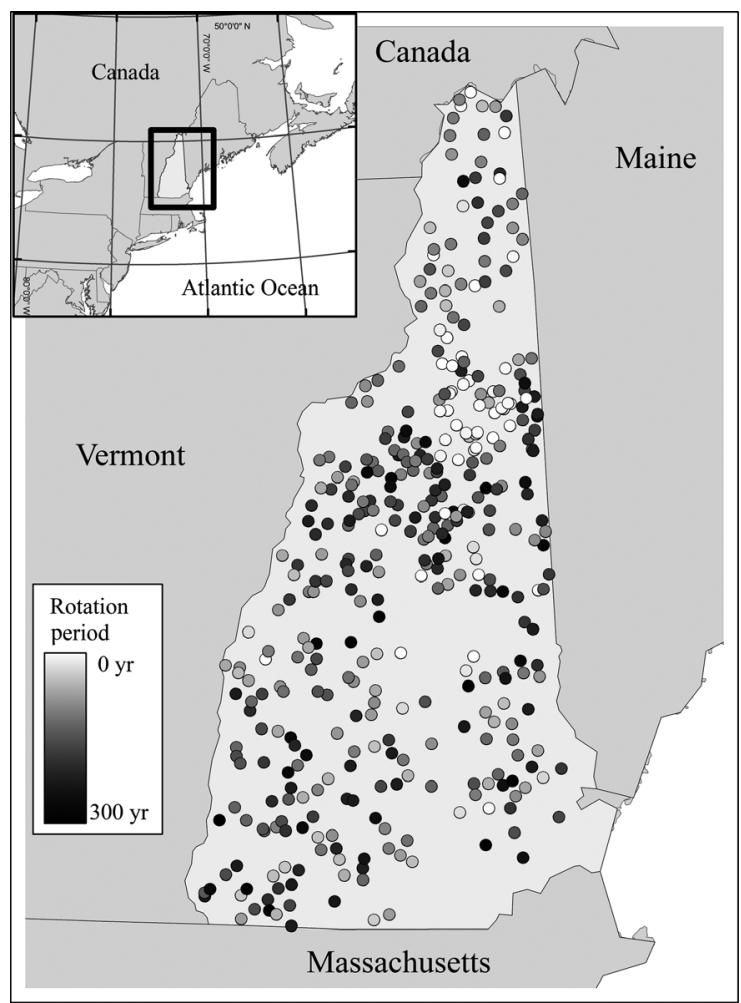

FIG. 2. The optimal rotation length, or period, for each of the 498 simulated sites. Generally, optimal rotation length was shorter in the northern third of New Hampshire, with very short lengths occurring at high elevations in the White Mountain National Forest (cluster of very short lengths in the eastern upper half of the state). calculated tree (Fig. 6) accounts for approximately one-half of the variation in the optimal rotation length across sites $\left(R^{2}=0.51\right)$ and has a residual $\mathrm{SD}$ of $21.6 \mathrm{yr}$ with a cross-validation SD of $31.9 \mathrm{yr}$. The branches of the tree reveal that the overall shortest rotation lengths are those sites with a relatively low timber growth rate $(<0.01269)$ and a high difference between the saturated and cleared albedo baselines $(>0.1269)$. These sites have a mean optimal rotation time of only $32.53 \mathrm{yr}$. Sites with the highest timber volume growth rate have the next shortest mean rotation time of $53.68 \mathrm{yr}$. The longest optimal rotation lengths are associated with very low growth rates and high timber prices.

Overall, the variables having the strongest influence on the optimal rotation length are the timber volume growth rate, the yearly storage of carbon within biomass in the stand (which is closely tied to volume growth), the difference between the saturated and cleared albedo baselines, the cleared albedo value, and the sawtimber stumpage price (Table 1). The yearly storage of carbon within biomass and the cleared albedo value do not show up in the tree because they are closely associated with the timber volume growth rate and the difference between the albedo baselines, respectively, which are both stronger predictors of optimal rotation length. In examining the influence of each variable on the net present value of each of the three ecosystem services, we find that the albedo difference, cleared albedo, and slope were most important for the NPV of albedo. For the NPV of carbon storage, the most influential site characteristics are the

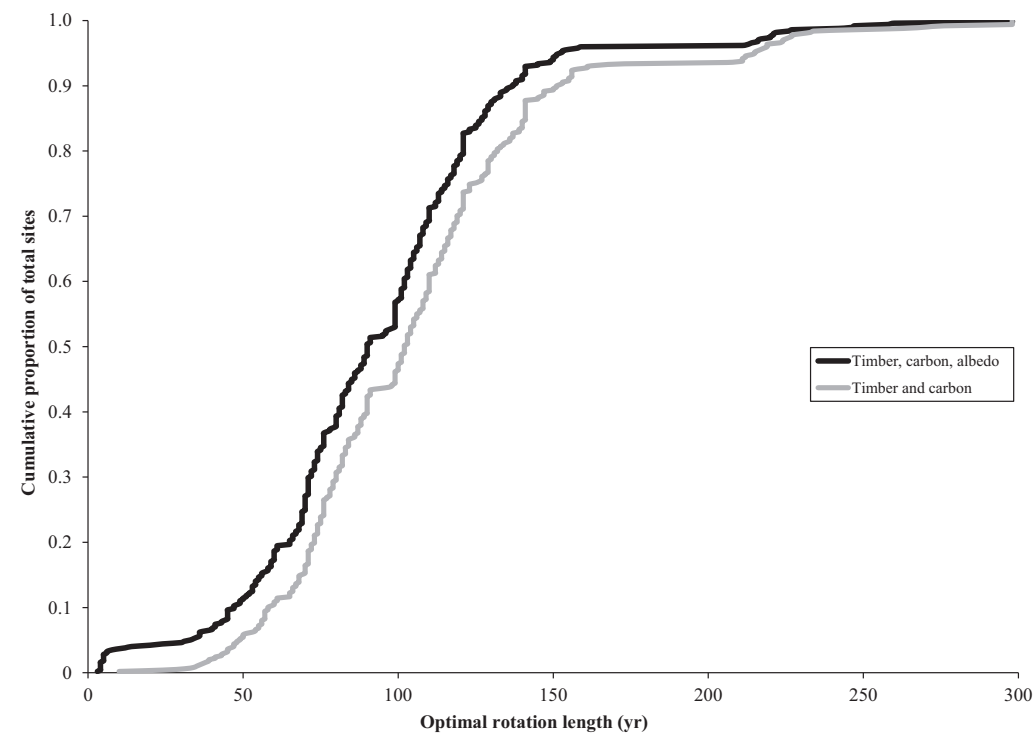

FIG. 3. A cumulative distribution chart showing optimal rotation lengths for all 498 sites when timber, carbon, and albedo were considered (black line), compared to when only timber and carbon were considered (gray line). Albedo generally shortened optimal rotation length, and in some cases, optimal rotation approached just $3 \mathrm{yr}$. 


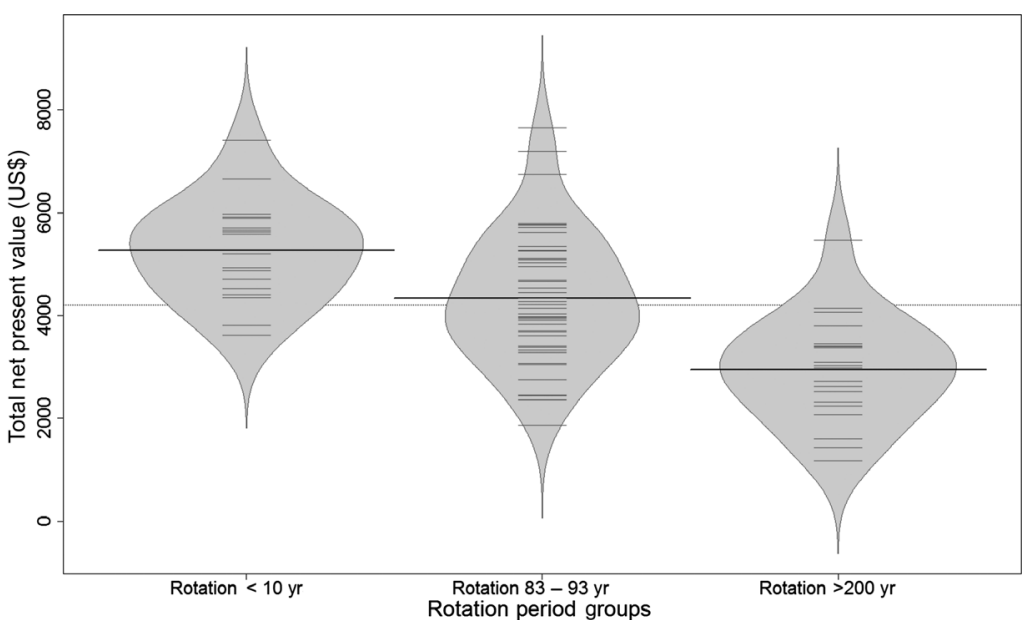

FIG. 4. A bean plot showing the total NPV for three groups of simulated forest sites. The groups were selected based on optimal rotation length. Each light line represents the NPV for one site, while the darker line represents the mean of the group. The width of the bean displays the distribution of sites within each group. The dotted line indicates the mean net present value of all three ecosystem services across all sites.
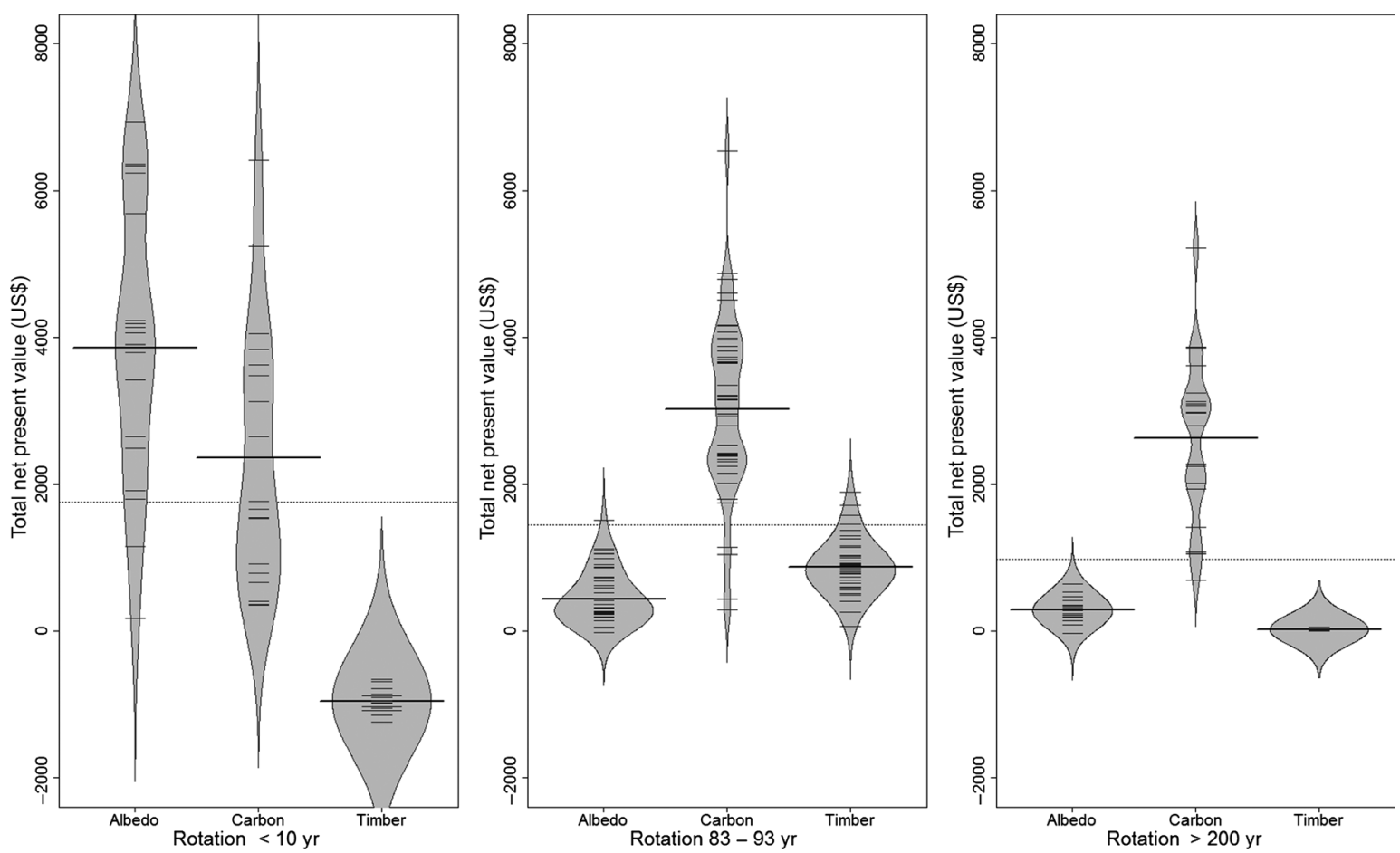

FIG. 5. Three bean plots showing the timber, carbon, and albedo NPV for each of the three groups of optimal rotation lengths. For sites with short optimal rotation lengths, albedo and carbon contributed significantly to the total NPV whereas timber harvest, through mowing costs, generated a net negative NPV. Carbon provided the majority of revenues for sites with both medium (middle) and long (right) rotation lengths. Components of plots are as in Fig. 4.

maximum carbon storage and the canopy saturation time. These carbon storage parameters, however, are not especially influential in the overall determination of optimal rotation length.
The baseline albedo for each site serves as an important variable in determining the optimal rotation length for the site. As calculated initially, the baseline for each site was based on mean values for each month 
over the 2002-2013 time period, then averaged across the years. When we changed the baselines to reflect either a $\Delta \alpha_{\max }$ scenario, by choosing the maximum cleared and minimum saturated albedos for each month, or a $\Delta \alpha_{\min }$ scenario, by choosing the minimum cleared and maximum saturated albedos for each month, the mean rotation length and total albedo NPVs were significantly different compared with when using the mean baseline (Table 2). The mean rotation length dropped to $59 \mathrm{yr}$ with the $\Delta \alpha_{\max }$ baseline and increased to $112 \mathrm{yr}$ with the $\Delta \alpha_{\min }$ baseline. The albedo net present value increased to $\$ 2317.27 /$ ha on average for the $\Delta \alpha_{\max }$ baseline, whereas for the $\Delta \alpha_{\min }$ baseline, the mean albedo net present value dropped to a negative value, at $-\$ 208.55 /$ ha.

\section{Discussion}

Incorporating surface albedo led to a decrease in optimal rotation lengths for forest sites across the state compared to when only timber and carbon were considered (Fig. 2). While this general finding mimics other studies incorporating albedo into an assessment of optimal rotation lengths (Thompson et al. 2009, Lutz and Howarth 2014), here we find that in some locations, the optimal rotation length approaches zero (3 years $<t<10$ years) at a small percentage of sites. While these do not suggest that continual harvest should be prescribed for such locations, given the importance of additional ecosystem services not incorporated in our analysis such as biodiversity protection and aesthetic and recreational values, they do suggest that approaches that limit harvest in an effort to store carbon may not provide the greatest bundle of economic benefits from some forest stands. This is of great interest to the burgeoning United States forest carbon market, as forest owners, including several in New England, have recently begun to apply for certification of carbon offsets through the California Air Resources Board offset program. Our results show several locations where a management strategy of a very long rotation length does not provide optimal climate benefits, suggesting that such strategies may be misguided without the inclusion of albedo, a finding consistent with a growing number of other studies (Bright et al. 2014, Lutz and Howarth 2014).

Furthermore our findings indicate that site-to-site optimal rotation lengths can vary substantially over very short distances in temperate forests. While much interest has been placed on albedo with respect to

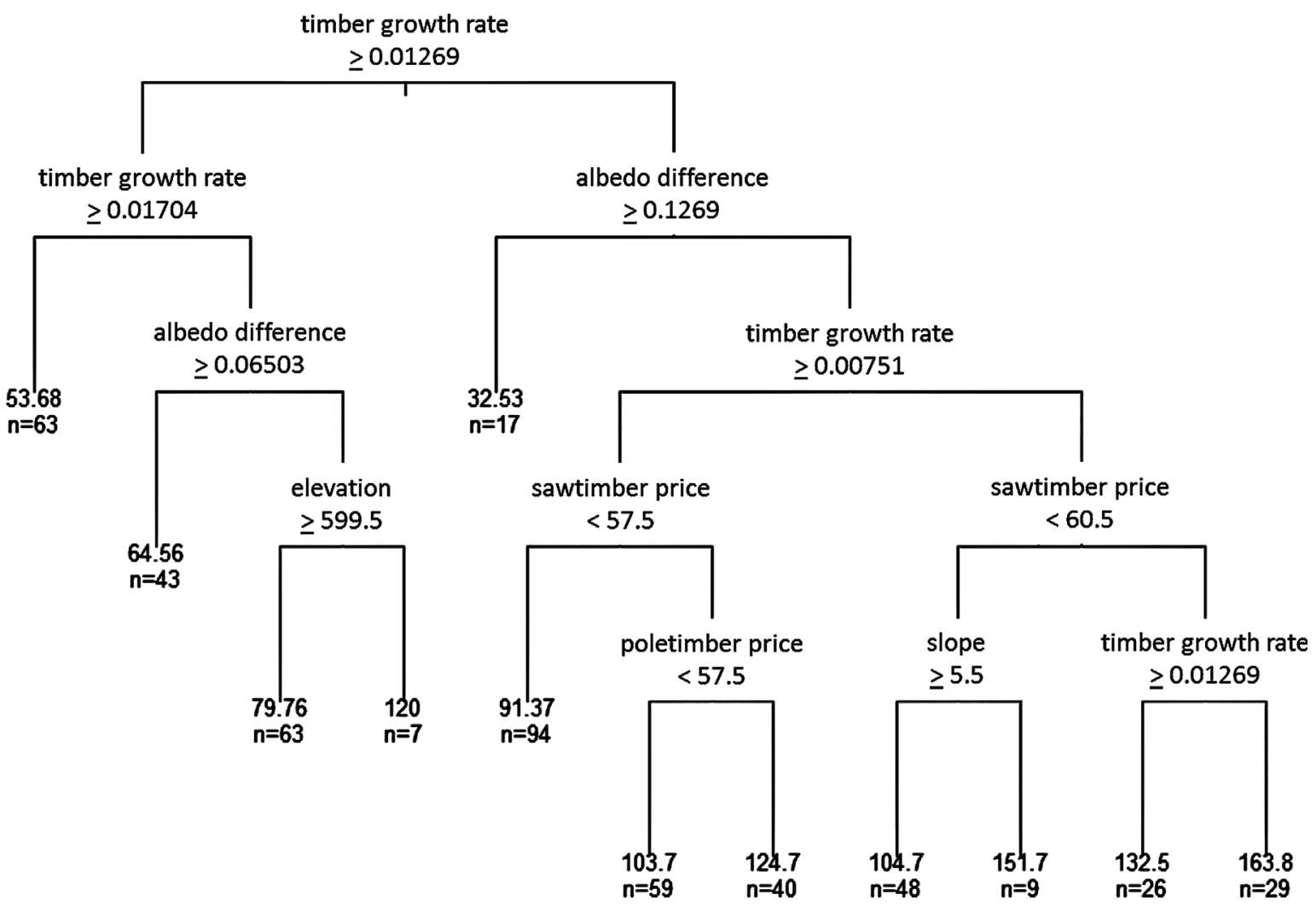

FIG. 6. The regression tree used to determine the importance of 19 predictor variables (Table 1) on optimal rotation length; $n$ represents the number of sites ultimately partitioned into each grouping. When the stated conditions are true, the tree proceeds to the left, when false to the right. Albedo difference refers to the magnitude of the difference between saturated and cleared baseline albedo for the site. All units are given in Table 1. 
TABLE 2. Choice of albedo baseline had a considerable effect on optimal rotation length for the modeled sites NPV $(P<0.0001$, $n=498)$.

\begin{tabular}{lcccc}
\hline Albedo baseline & Rotation length $(\mathrm{yr})$ & Saturated albedo & Cleared albedo & Albedo NPV (\$/ha) \\
\hline 10-year baseline & $94(44)$ & $0.136(0.0215)$ & $0.193(0.0403)$ & $512.76(823.64)$ \\
High albedo & $59(46)$ & $0.11(0.0164)$ & $0.259(0.0628)$ & $2317.27(2350.62)$ \\
Low albedo & $112(49)$ & $0.171(0.0318)$ & $0.14(0.0217)$ & $-208.55(243.32)$ \\
\hline
\end{tabular}

Notes: Standard deviation (SD) is shown in parentheses. Selecting a reference year where snowfall and albedo are considerably higher generated a nearly 40-yr shortening in rotation length, on average, across all the sites. The opposite effect was true for selecting a low-albedo reference year, whereby optimal rotations increased on average by nearly $20 \mathrm{yr}$.

forest management in boreal zones with monospecific or low-diversity stands (Bright et al. 2011, 2014, Kuusinen et al. 2014a), New Hampshire's forests often contain a wide assortment of species that range from temperate to boreal. Tree species diversity allows for a variety of species-specific growth rates and an array of potential forest products and prices to influence the trade-off of timber, carbon, and albedo ecosystem services. As a result, sites that share similar climates yet differ substantially in species mixes and growth rates can yield drastically different mixes of ecosystem services and thus different optimal rotation lengths. Thus, we believe it is critical that forest policies that seek to maximize climate benefits from forests in New Hampshire pay close attention to site-specific characteristics. In other words, generalized models of forest growth or coarse albedo measurements may not be sufficient for measuring and comparing overall tradeoffs of these climate services since such trade-offs are easily influenced by very slight changes. New Hampshire is situated at a precipitous boundary in which subtle variations in site snowfall or growth rates may change optimal harvest strategies dramatically. It seems clear that site-specific and stand-level research is needed to delineate these boundaries in other states in New England.

Our regression tree analysis of the most important stand variables that influenced rotation length led to several insights about site characteristics. The most important variable related to the optimal rotation length was the rate that forest production was translated into timber volume. At forest sites that grew quickly and generated high-value timber products, such as sites with pine and maple species, the total duration of time that albedo radiative forcing was generated before canopy cover lowered surface reflectivity was short, and thus there was a minimal benefit toward managing for albedo (short harvest), compared to longer harvests that maximized timber and carbon storage. In contrast, at sites where timber growth was very slow, such as high-elevation sites with low-productivity forests, the net benefits from timber and carbon took significant time to materialize, and thus, short rotation lengths that generated albedo benefits were optimal.

In addition to our regression tree analysis, we performed a sensitivity analysis based on the three most influential site variables from the regression tree (timber growth rate, carbon storage rate, and stumpage price) and examined their influence on optimal rotation period. When we reran our simulations with a $\pm 10 \%$ change in each variable, we found that the model was most sensitive to subtle changes in stumpage price and carbon growth rate (Appendix: Fig. S12). The timber growth rate did not have a significant influence on optimal rotation periods, however, at this level of adjustment $(10 \%)$. When all three variables were adjusted in the same direction, the optimal rotation period across all 498 sites was significantly different than in our original runs. Thus, it does not appear that our model is particularly sensitive to subtle variations in any of these variables, but that changes to variables that are compounding (for example, timber growth rate and stumpage price) can yield statistically significant differences when compared to a base case. While we did not analyze how the choice of discount rate and trajectory may influence the model, we hypothesize that this choice will have a considerable effect.

It is important to note that the costs of mowing precluded the optimal rotation length from reaching 1 year and instead, the shortest optimal rotation lengths were 3-5 years. Short rotation lengths like this can in some contexts be used in order to improve habitat for several bird (Weidman and Litvaitis 2011), insect (Wilson et al. 2014), and endangered species such as the New England cottontail (Sylvilagus tranitionalis) (Buffum et al. 2011). Additionally, early successional habitat created by this rotation length is also critical for understory plant diversity (Swanson et al. 2011). Because of these benefits, state wildlife agencies and federal programs commonly provide financial assistance to pay for the costs of mowing and early timber harvest (Oehler 2003, Buffum et al. 2014). In these cases, very short rotation lengths that are subsidized in this way may provide even more financial benefits to the manager of the property.

The difference in albedo between cleared ground and mature forest was a significant factor in determining the optimal rotation length. These estimates influenced the total magnitude of the radiative forcing benefit generated by forest harvest, and therefore the greater the difference between these two values, the larger the benefit obtained by having a short rotation 
length. Previous research in boreal ecosystems has indicated that the difference between cleared and mature forest albedo matters greatly in assessing climate trade-offs (Bright et al. 2011, 2012). Our results suggest that in regions where snow is intermittent throughout the winter, the accumulation of snow, and hence the wintertime albedo, has a major influence on the rotation length as well. Thus, heavy snow events and cold winters that foster consistently high surface albedo can dramatically change optimal rotation strategy compared to warmer, lower snowfall winters.

While previous research has investigated changes in albedo at the beginning and end of the winter season due to temperature increases (Bright et al. 2014), in New Hampshire, surfaces do not consistently stay snow-covered throughout the winter, and thus individual snow events can alter annual albedo measurements drastically. Subsequently, we found that choosing a baseline with which to compare historical and future albedos to calculate net benefits is quite influential. When we altered our assumptions regarding baseline albedo to represent two different scenarios, we calculated a substantial change in optimal rotation length across all forest sites $(P<0.0001)$. It is therefore critical that site-specific measures of albedo at high temporal and spatial resolution be available to properly assess the appropriateness of climate mitigation projects focused on forests in the state.

Our modeling framework was not capable of addressing soil carbon, which can account for nearly 50\% of total ecosystem carbon in forests in New Hampshire (Fahey et al. 2005). While forest soil carbon is still generally understudied in the context of carbon accounting (Petrenko and Friedland 2014), several authors have utilized data from chronosequences of forest soils, and concluded that clear-cut harvest can lead to losses of soil organic carbon (SOC), particularly when a large percentage of biomass is removed (Johnson et al. 2010). Subtle losses in the deep mineral soil may also lead to overall belowground carbon losses to the atmosphere (Vario et al. 2014). However, a meta-analysis of 26 studies examining soil carbon found that there was little effect of harvest upon the A horizon and no significant effect on average on B horizon and whole soils (Johnson and Curtis 2001). Thus, while there is no agreed-upon consensus regarding the fate of forest soil carbon post-harvest at all levels, it is likely that heavy harvest under short rotation periods may lead to losses in the soil carbon pool. Incorporating a loss of $\sim 10 \%$ of the pool (Johnson and Curtis 2001, Johnson et al. 2010) in our model results would likely lengthen rotation periods slightly, but the short-rotation sites where albedo is the major contributor would likely be unaffected due to the magnitude of albedo NPV. In any event, this component of the forest carbon budget warrants further attention in FACT modeling studies moving forward.
While analyses that incorporate the effect of partial or selective harvest exist regarding trade-offs between timber and carbon (e.g., Gutrich and Howarth 2007), the influence of this type of management on albedo is not completely understood. Kuusinen et al. (2014a) report that a thinning operation did not influence shortwave albedo in managed pine stands in Finland, possibly due to the influence of the understory. The presence of standing biomass can drastically impact albedo, with even standing dead trees substantially altering measurements taken by satellite (O'Halloran et al. 2014). Thus, although partial harvests provide opportunities for the maintenance of several ecosystem services in managed forest landscapes (Schwenk et al. 2012), we do not anticipate that this type of management will generate albedo benefits at a significant scale. Further analyses of the effect of thinning on albedo via fine-scale imagery in temperate forest stands are necessary moving forward to address the question of partial harvest in a more complete manner.

We did not incorporate the myriad complexities of a changing climate on forest ecosystems into this modeling study. Generally, the New England region of the United States is expected to be warmer and slightly wetter, with increases in annual regional surface temperatures between $2.9^{\circ} \mathrm{C}$ and $5.3^{\circ} \mathrm{C}$ and an increase in wintertime precipitation of $11-14 \%$ by 2070-2099 (Hayhoe et al. 2007). These changes will undoubtedly influence forest species composition over the 21 st century, with more southerly species such as oaks and hickories becoming significantly more dominant by 2100 (Tang et al. 2012) and the continued migration of evergreen spruce-fir forests further upslope (Groffman et al. 2012). We expect this to result in markedly different flows of timber, carbon (Tang et al. 2014), and albedo decay rates, with the overall influence being an increased ability of New Hampshire forest stands to store carbon and generate valuable sawtimber stock. Such shifts in climate will also likely decrease the total days with snowfall and snow pack (Hayhoe 2007), limiting the influence of albedo and lengthening optimal rotation periods. Our future work to incorporate more robust forest landscape models (Thompson et al. 2011) and albedo measurements and models (Burakowski et al. 2015) will help address these current uncertainties.

In conclusion, this research details a modeling approach to address questions about trade-offs that exist between multiple ecosystem services in temperate forests in New Hampshire. However, the optimal rotation lengths calculated and reported in this study should not be interpreted as prescriptive. Practical decisions regarding optimal forest harvest strategy require balancing multiple objectives and preferences and often involve deciding between a large group of ecosystem services which may or may not have defined economic values. Along those lines, other biophysical influences 
on climate from forests such as surface roughness and surface and latent energy transfer were not included in our model, although they have been examined elsewhere (Zhao and Jackson 2014). While these properties affect localized surface temperature, their overall impact at the global scale is difficult to measure (Davin and de Noblet-Ducoudré 2010). Future work will incorporate the influence of cloud albedo on atmospheric transmissivity, the influence of climate change on snowfall depth and subsequently snow albedo (Burakowski et al. 2015), forest successional dynamics, particularly tree species migration, and other valuable ecosystem services such as biodiversity and wildlife habitat.

\section{ACKNOWLEDGMents}

This work was funded primarily through the New Hampshire Experimental Program to Stimulate Cooperative Research (EPSCoR) Project "Ecosystems and Society" from the National Science Foundation. Additional funding was obtained through the Southern Research Station of the U.S. Forest Service and the Junior Research Scholarship program at Dartmouth College. The authors would like to thank Tom O'Halloran and Georgia Mavrommati for comments on the manuscript. D. A. Lutz would like to thank Queso and Waffle and E. A. Burakowski would like to thank Cory for their contributions to the development of the manuscript. E. A. Burakowski would also like to thank the USDA Forest Service Northern Research Station for their assistance relating to this manuscript.

\section{Literature Cited}

Anderson, R. G., et al. 2011. Biophysical considerations in forestry for climate protection. Frontiers in Ecology and the Environment 9:174-182.

Bechtold, W. A., and P. L. Patterson. 2005. Enhanced forest inventory and analysis program - national sampling design and estimation procedures. Technical Report SRS-80. USDA Forest Service, Southern Research Station, Asheville, North Carolina, USA.

Betts, R. A. 2000. Offset of the potential carbon sink from boreal forestation by decreases in surface albedo. Nature 408:187-190.

Bonan, G. B. 2008. Forests and climate change: forcings, feedbacks, and the climate benefits of forests. Science 320:1444-1449.

Bonan, G. B., F. S. Chapin, and S. L. Thompson. 1995. Boreal forest and tundra ecosystems as components of the climate system. Climatic Change 29:145-167.

Breiman, L., J. Friedman, C. Stone, and R. Olshen. 1984. Classification and regression trees. WIREs Data Mining and Knowledge 1:14-23.

Bright, R. M., C. Antón-Fernández, R. Astrup, F. Cherubini, M. Kvalevåg, and A. H. Strømman. 2014. Climate change implications of shifting forest management strategy in a boreal forest ecosystem of Norway. Global Change Biology 20:607-621.

Bright, R. M., R. Astrup, and A. H. Strømman. 2013. Empirical models of monthly and annual albedo in managed boreal forests of interior Norway. Climatic Change 120:183-196.

Bright, R. M., F. Cherubini, and A. H. Strømman. 2012. Climate impacts of bioenergy: inclusion of carbon cycle and albedo dynamics in life cycle impact assessment. Environmental Impact Assessment Review 37:2-11.

Bright, R. M., A. H. Strømman, and G. P. Peters. 2011. Radiative forcing impacts of boreal forest biofuels: a scenario study for Norway in light of albedo. Environmental Science Technology 45:7570-7580.

Buffum, B., S. R. McWilliams, and P. V. August. 2011. A spatial analysis of forest management and its contribution to maintaining the extent of shrubland habitat in southern New England, United States. Forest Ecology and Management 262:1775-1785.

Buffum, B., C. Modisette, and S. R. McWilliams. 2014. Encouraging family forest owners to create early successional wildlife habitat in Southern New England. PLoS ONE 9:e89972.

Burakowski, E. A., S. V. Ollinger, L. Lepine, C. B. Schaaf, Z. Wang, J. E. Dibb, D. Y. Hollinger, J. Kim, A. Erb, and M. Martin. 2015. Spatial scaling of reflectance and surface albedo over a mixed-use, temperate forest landscape during snow-covered periods. Remote Sensing of Environment 158:465-477.

Canadell, J. G., and M. R. Raupach. 2008. Managing forests for climate change mitigation. Science 320:1456-1457.

Chapin, F. S., et al. 2000. Arctic and boreal ecosystems of western North America as components of the climate system. Global Change Biology 6:211-223.

Cherubini, F., R. M. Bright, and A. H. Strømman. 2012. Site-specific global warming potentials of biogenic $\mathrm{CO}_{2}$ for bioenergy: contributions from carbon fluxes and albedo dynamics. Environmental Research Letters 7:045902.

Cherubini, F., R. M. Bright, and A. H. Strømman. 2013. Global climate impacts of forest bioenergy: what, when and how to measure? Environmental Research Letters 8:014049.

Chladná, Z. 2007. Determination of optimal rotation period under stochastic wood and carbon prices. Forest Policy and Economics 9:1031-1045.

Crookston, N. L., and G. E. Dixon. 2005. The forest vegetation simulator: a review of its structure, content, and applications. Computers and Electronics in Agriculture 49:60-80.

Davin, E. L., and N. de Noblet-Ducoudré. 2010. Climatic impact of global-scale deforestation: radiative versus nonradiative processes. Journal of Climate 23:97-112.

Dixon, G. 2002. Essential FVS: a user's guide to the Forest Vegetation Simulator. USDA Forest Service, Fort Collins, Colorado, USA.

Fahey, T. J., et al. 2005. The biogeochemistry of carbon at Hubbard Brook. Biogeochemistry 75:109-176.

Fahey, T. J., P. B. Woodbury, J. J. Battles, C. L. Goodale, S. P. Hamburg, S. V. Ollinger, and C. W. Woodall. 2010. Forest carbon storage: ecology, management, and policy. Frontiers in Ecology and the Environment 8:245-252.

Galik, C. S., B. C. Murray, S. Mitchell, and P. Cottle. 2014. Alternative approaches for addressing non-permanence in carbon projects: an application to afforestation and reforestation under the Clean Development Mechanism. Mitigation and Adaptation Strategies for Global Change. http://dx.doi.org/10.1007/s11027-014-9573-4

Gibbs, H. K., S. Brown, J. O. Niles, and J. A. Foley. 2007. Monitoring and estimating tropical forest carbon stocks: making REDD a reality. Environmental Research Letters 2:045023.

Griscom, B., D. Shoch, B. Stanley, R. Cortez, and N. Virgilio. 2009. Sensitivity of amounts and distribution of tropical forest carbon credits depending on baseline rules. Environmental Science \& Policy 12:897-911. 
Groffman, P. M., et al. 2012. Long-term integrated studies show complex and surprising effects of climate change in the northern hardwood forest. BioScience 62:1056-1066.

Gutrich, J., and R. B. Howarth. 2007. Carbon sequestration and the optimal management of New Hampshire timber stands. Ecological Economics 62:441-450.

Hall, D. K., and G. A. Riggs. 2007. Accuracy assessment of the MODIS snow products. Hydrological Processes 21:1534-1547.

Hardiman, B. S., C. M. Gough, A. Halperin, K. L. Hofmeister, L. E. Nave, G. Bohrer, and P. S. Curtis. 2013. Maintaining high rates of carbon storage in old forests: a mechanism linking canopy structure to forest function. Forest Ecology and Management 298:111-119.

Hayhoe, K., et al. 2007. Past and future changes in climate and hydrological indicators in the US Northeast. Climate Dynamics 28:381-407.

Hilt, D., and R. Teck. 1989. NE-TWIGS: an individual-tree growth and yield projection system for the northeastern United States. Compiler 7(2):10-16.

Hurteau, M. D., B. A. Hungate, G. W. Koch, M. P. North, and G. R. Smith. 2013. Aligning ecology and markets in the forest carbon cycle. Frontiers in Ecology and the Environment 11:37-42.

Jackson, R. B., et al. 2008. Protecting climate with forests. Environmental Research Letters 3:044006.

Jenkins, J. C., D. C. Chojnacky, L. S. Heath, and R. A. Birdsey. 2003. National scale biomass estimators for United States tree species. Forest Science 49:12-35.

Johnson, D. W., and P. S. Curtis. 2001. Effects of forest management on soil $\mathrm{C}$ and $\mathrm{N}$ storage: meta analysis. Forest Ecology and Management 140:227-238.

Johnson, K., F. N. Scatena, and Y. Pan. 2010. Short- and long-term responses of total soil organic carbon to harvesting in a northern hardwood forest. Forest Ecology and Management 259:1262-1267.

Kaipainen, T., J. Liski, A. Pussinen, and T. Karjalainen. 2004. Managing carbon sinks by changing rotation length in European forests. Environmental Science \& Policy 7:205-219.

Kalogirou, S. A. 2009. Solar energy engineering: processes and systems. Academic Press, Burlington, Massachusetts, USA.

Keith, H., D. Lindenmayer, B. Mackey, D. Blair, L. Carter, L. McBurney, S. Okada, and T. Konishi-Nagano. 2014. Managing temperate forests for carbon storage: impacts of logging versus forest protection on carbon stocks. Ecosphere 5:art75.

Kirschbaum, M. U. F., D. Whitehead, S. M. Dean, P. N Beets, J. D. Shepherd, and A. G. E. Ausseil. 2011. Implications of albedo changes following afforestation on the benefits of forests as carbon sinks. Biogeosciences 8:3687-3696.

Klein, A. G., and J. Stroeve. 2002. Development and validation of a snow albedo algorithm for the MODIS instrument. Annals of Glaciology 34:8.

Kuusinen, N., P. Lukeš, P. Stenberg, J. Levula, E. Nikinmaa, and F. Berninger. 2014a. Measured and modelled albedos in Finnish boreal forest stands of different species, structure and understory. Ecological Modelling 284:10-18.

Kuusinen, N., E. Tomppo, Y. Shuai, and F. Berninger. 2014b. Effects of forest age on albedo in boreal forests estimated from MODIS and Landsat albedo retrievals. Remote Sensing of Environment 145:145-153.

Lamson, N. I., and W. B. Leak, . 2000. Guidelines for applying group selection harvesting. USDA Forest Service Northeastern Area, Newtown Square, Pennsylvania, USA. http://na.fs.fed.us/stewardship/pubs/guidelines/guidelines. htm
Law, B. E., and M. E. Harmon. 2011. Forest sector carbon management, measurement and verification, and discussion of policy related to climate change. Carbon Management 2:73-84.

Le Quéré, C., et al. 2013. The global carbon budget 1959-2011. Earth System Science Data 5:165-185.

Leak, W. B. 2005. Effects of small patch cutting on sugar maple regeneration in New Hampshire northern hardwoods. Northern Journal of Applied Forestry 22(1):68-70.

Liski, J., A. Pussinen, K. Pingoud, R. Mäkipää, and T. Karjalainen. 2011. Which rotation length is favourable to carbon sequestration? Canadian Journal of Forest Research 31(11):2004-2013

Lukeš, P., M. Rautiainen, T. Manninen, P. Stenberg, and M. Mõttus. 2014. Geographical gradients in boreal forest albedo and structure in Finland. Remote Sensing of Environment 152:526-535.

Lukeš, P., P. Stenberg, and M. Rautiainen. 2013. Relationship between forest density and albedo in the boreal zone. Ecological Modelling 261-262:74-79.

Lutz, D. A., and R. B. Howarth. 2014. Valuing albedo as an ecosystem service: implications for forest management. Climatic Change 124:53-63.

Malmsheimer, R. W., J. L. Bowyer, J. S. Fried, E. Gee, R. L. Izlar, R. A. Miner, I. A. Munn, E. Oneil, and W. C. Stewart. 2011. Managing forests because carbon matters: integrating energy, products, and land management policy. Journal of Forestry 109(7S):S7-S50.

McRoberts, R. E., W. A. Bechtold, P. L. Patterson, C. T. Scott, and G. A. Reams. 2005. The enhanced forest inventory and analysis program of the USDA Forest Service: historical perspective and announcements of statistical documentation. Journal of Forestry 3(6):304-308.

Mika, A. M., and W. S. Keeton. 2014. Net carbon fluxes at stand and landscape scales from wood bioenergy harvests in the US Northeast. GCB Bioenergy 7(3):438-454.

Moisen, G. G., and T. S. Frescino. 2002. Comparing five modelling techniques for predicting forest characteristics. Ecological Modelling 157:209-225.

Nair, A., A. C. Thomas, and M. E. Borsuk. 2013. Interannual variability in the timing of New England shellfish toxicity and relationships to environmental forcing. Science of the Total Environment 447:255-66.

NASA. 2009. Surface Meteorology and Solar Energy (SSE) Release v.6.0 NASA Langly Atmospheric Science Data Center. http://power.larc.nasa.gov/cgi-bin/cgiwrap/solar/sse.cgi?+s06

Nordhaus, W. 2008. A question of balance: weighing the options on global warming policies. Yale University Press, New Haven, Connecticut, USA.

Nordhaus, W. D. 1993. Optimal greenhouse-gas reductions and tax policy in the "dice" model. American Economic Review 83:313-317.

Nordhaus, W. D. 2010. Economic aspects of global warming in a post-Copenhagen environment. Proceedings of the National Academy of Sciences USA 107:11721-11726.

Nunery, J. S., and W. S. Keeton. 2010. Forest carbon storage in the northeastern United States: net effects of harvesting frequency, post-harvest retention, and wood products. Forest Ecology and Management 259:1363-1375.

Oehler, J. D. 2003. State efforts to promote early-successional habitats on public and private lands in the northeastern United States. Forest Ecology and Management 185:169-177.

O'Halloran, T. L., S. A. Acker, V. M. Joerger, J. Kertis, and B. E. Law. 2014. Postfire influences of snag attrition 
on albedo and radiative forcing. Geophysical Research Letters 41:9135-9142.

Otto, J., et al. 2014. Forest summer albedo is sensitive to species and thinning: how should we account for this in Earth system models? Biogeosciences 11:2411-2427.

Petrenko, C. L., and A. J. Friedland. 2014. Mineral soil carbon pool responses to forest clearing in northeastern hardwood forests. GCB Bioenergy. doi:10.1111/gcbb.12221.

Price, C., and R. Willis. 2011. The multiple effects of carbon values on optimal rotation. Journal of Forest Economics 17:298-306.

Ray, D. G., M. R. Saunders, and R. S. Seymour. 2009. Recent changes to the northeast variant of the forest vegetation simulator and some basic strategies for improving model outputs. Northern Journal of Applied Forestry 26(1):31-34.

Russell, M. B., A. R. Weiskittel, and J. A. Kershaw. 2013. Benchmarking and calibration of forest vegetation simulator individual tree attribute predictions across the northeastern United States. Northern Journal of Applied Forestry 30:75-84.

Schaaf, C. B., et al. 2002. First operational BRDF, albedo nadir reflectance products from MODIS. Remote Sensing of Environment 83:135-148.

Schaaf, C. B., J. Liu, F. Gao, and A. H. Strahler. 2011. Aqua and Terra MODIS albedo and reflectance anisotropy products. Pages 549-561 in B. Ramachandran, C. O. Justice, and M. J. Abrams, editors. Land remote sensing and global environmental change. Springer, New York, New York, USA.

Schwenk, W. S., T. M. Donovan, W. S. Keeton, and J. S. Nunery. 2012. Carbon storage, timber production, and biodiversity: comparing ecosystem services with multi-criteria decision analysis. Ecological Applications 22:1612-1627.

Sendak, P. E., R. C. Abt, and R. J. Turner. 2003. Timber supply projections for northern New England and New York: integrating a market perspective. Northern Journal of Applied Forestry 20:175-185.

Sturm, M. 2005. Changing snow and shrub conditions affect albedo with global implications. Journal of Geophysical Research 110:G01004.

Swanson, M. E., J. F. Franklin, R. L. Beschta, C. M. Crisafulli, D. A. DellaSala, R. L. Hutto, D. B. Lindenmayer, and F. J. Swanson. 2011. The forgotten stage of forest succession: early-successional ecosystems on forest sites. Frontiers in Ecology and the Environment 9:117-125.

Tang, G., B. Beckage, and B. Smith. 2012. The potential transient dynamics of forests in New England under historical and projected future climate change. Climatic Change 114:357-377.
Tang, G., B. Beckage, and B. Smith. 2014. Potential future dynamics of carbon fluxes and pools in New England forests and their climatic sensitivities: a model-based study. Global Biogeochemical Cycles 28:286-299.

Thompson, J. R., D. R. Foster, R. Scheller, and D. Kittredge. 2011. The influence of land use and climate change on forest biomass and composition in Massachusetts, USA. Ecological Applications 21:2425-2444.

Thompson, M. P., D. Adams, and J. Sessions. 2009. Radiative forcing and the optimal rotation age. Ecological Economics 68:2713-2720.

Tittmann, P., and S. Yeh. 2013. A framework for assessing the life cycle greenhouse gas benefits of forest bioenergy and biofuel in an era of forest carbon management. Journal of Sustainable Forestry 32:108-129.

van Kooten, G. C., C. S. Binkley, and G. Delcourt. 1995. Effect of carbon taxes and subsidies on optimal forest rotation age and supply of carbon services. American Journal of Agricultural Economics 77:365.

Vario, C. L., R. A. Neurath, and A. J. Friedland. 2014. Response of mineral soil carbon to clear-cutting in a northern hardwood forest. Soil Science Society of America Journal 78:309.

Weidman, T., and J. A. Litvaitis. 2011. Are small habitat patches useful for grassland bird conservation? Northeastern Naturalist 18:207-216.

Williams, C. A., M. K. Vanderhoof, M. Khomik, and B. Ghimire. 2014. Post-clearcut dynamics of carbon, water and energy exchanges in a midlatitude temperate, deciduous broadleaf forest environment. Global Change Biology 20:992-1007.

Wilson, M. K., W. H. Lowe, and K. H. Nislow. 2014. Family richness and biomass of understory invertebrates in early and late successional habitats of northern New Hampshire. Journal of Forestry 112:337-345.

Wykoff, W. R., N. L. Crookston, and A. R. Stage. 1982. User's guide to the stand prognosis model. Technical Report INT-22. USDA Forest Service Intermountain Forest and Range Experiment Station, Ogden, Utah, USA.

Yaussy, D. A. 2000. Comparison of an empirical forest growth and yield simulator and a forest gap simulator using actual 30 -year growth from two even-aged forests in Kentucky. Forest Ecology and Management 126:385-398.

Zhao, K., and R. B. Jackson. 2014. Biophysical forcings of land-use changes from potential forestry activities in North America. Ecological Monographs 84:329-353.

Zhu, K., C. W. Woodall, and J. S. Clark. 2012. Failure to migrate: lack of tree range expansion in response to climate change. Global Change Biology 18:1042-1052.

\title{
SUPPORTING INFORMATION
}

Additional supporting information may be found in the online version of this article at http://onlinelibrary.wiley.com/ doi/10.1890/14-2207.1/suppinfo

\author{
Data Availability
}

Data associated with this paper have been deposited in Dryad: http://dx.doi.org/10.5061/dryad.5vv6t 